\title{
The Klein bottle of digital identity
}

\author{
Kimberly Cass ${ }^{1}$
}

Published online: 29 May 2021

(c) The Author(s), under exclusive licence to Springer-Verlag London Ltd., part of Springer Nature 2021

Some assert that a person can by "reproduced" digitally; I'm not so sure. To examine possible challenges inherent with this assertion, consider how people are currently represented on digital platforms.

What makes you “you?" This perennial question of identity, or essential nature, can be apprehended from inside-out, what you experience of yourself, and from outside-in, what others experience of you.

From the inside-out, what you sense, feel and know about yourself is "something" which is symbiotically hosted on an amalgam of the ways you have encountered, combined, attended to, ignored and interpreted your life experience. You know that you wake up as the same person who went to bed the night before. You know that your preferences, your memories, your skills, and your interactions with your communities are uniquely yours. This essential "something," beyond the characteristics and attributes which make up your life, persists through time and is immediate, un-self-conscious, and unconstructed. Essence "leaks out" from what you do throughout the course of your daily life, and is natural, emergent, "scriptless," spontaneous, serendipitous, and unexpected. Your essence can be apprehended in the way you do something when you are not looking.

Your essence is composed of and revealed through seemingly inconsequential moments and un-self-consciously emerges independent of what you consciously choose for people to see. Your presence is experienced and somehow evokes an often-unconscious "relational recognition" in another that allows them to "know" you in a special way in their lives, just as you know them in a special way in your life. Usually, this knowledge results from being together throughout time, doing mostly ordinary things, although there may be shared peak experiences as well. One "knows" you by being with you, by noticing gestures, turns of phrases, and intonations, which act as windows to apprehend

Kimberly Cass

kimberly_cass@redlands.edu

1 School of Business, University of Redlands, Redlands, CA 92373, USA "something more" about you. These touchstones provide portals into the "something" essential, ineffable, and immaterial which defines you. A "just-beyond-the-reach of" you, which is "known without knowing" and which reveals something profound from the inconsequential. Beyond attributes and characteristics, your essence is revealed throughout time as a felt sense, or qualitative feel which allows another realtime transitory glimpses that reveal who you are.

What changes when the primary way of encountering another occurs over electronic media? What happens when relationships move from real-life onto digital platforms?

Social media supports some in-real-life (IRL) attributes of relationships while it is incapable of preserving others. Since much of the IRL day-to-day "being with" others is gone, the Aristotelian question arises:

If you do something IRL, but did not document it on social media, and thus nobody sees it there, did it really happen? Did you really do it?

It is not just whether something "happens" digitally, but was it authentic or contrived? Social media demands a memorable image, and paradoxically, you lose yourself authentically "being" in the present moment when you attempt to create that image when you try to convey yourself over social media. You now must create a movie-life in which you are the star. You must struggle to externally depict your internal state of lived experience by taking a moment out of the river of time to create an enduring image. You fix something which is fleeting and passing to create an eternal present in which you are always pretending to be yourself in a bygone moment.

To artfully present your life, you can no longer just "live it," now you must bifurcate who you are in the present moment to become a director and an actor to portray your life in another moment for others to consume. You must now divorce yourself from a remembered emotion or experience to become the actor who will portray it. You lose the authentic self-identity, which other-than-consciously coalesces and responds naturally to any person or situation you encounter when you try to characterize the encounter with conscious poses, lighting, photo-angles, and props to convey 
your identity. A byproduct supplants the actual experience or event, as you have created a reenactment of what once was "real." The audience encounters and responds to this contrived reality which originally had its basis in something real, but is, in itself, merely a rendition, devoid of the original's spontaneity and life. You have substituted an authentic experience/response/emotion with what an audience would recognize or impute about it from a curated image. Acting for the external gaze, your goal is to create a condition for audience response. Your "likes," attention, and positive comments justify your "being" in your contrived world.

Contrast IRL and virtual versions of a Celebration of Life. At an IRL Celebration of Life attendees can get some sense of the deceased's essence by hearing and telling stories about and seeing candid images of them. Using personal reflections and experiences you attempt to characterize what someone meant to you in your life while you mourn the lack or hole that their death will leave. These remembrances reinforce the feeling of going through life with someone, what you notice, and what you miss when that person dies. Thoughts and memories of someone will be taken forward by others and remembered when sparked by places, songs, words, environments, times of year. In many ways, the "container" of our essence is formed by those who truly "know" us. "The song is ended, but the melody lingers on"- that elusive "something more" that remains in the hearts of those who have truly encountered "someone."

At an Instagram or Facebook "friend's" virtual Celebration of Life descriptions of life events are accompanied by carefully curated images showing the deceased exemplifying an "ideal" against exotic backdrops in perfect sartorial splendor with flawless lighting and camera angle. By carefully composing and constructing each imposed image, they are always depicted in the way that they want to be seen, with each image more breath-taking and awe-inspiring than the last. While the attendees, assuming closeness where none exists, "ooh" and "aah" over these eternal images of perfection, sanitized of anything the person does not want them to see or know, the essence of the deceased, silently and unseen, slowly dissipates into the background. Was such a digital person ever "really" there?

Curmudgeon Corner Curmudgeon Corner is a short opinionated column on trends in technology, arts, science and society, commenting on issues of concern to the research community and wider society. Whilst the drive for super-human intelligence promotes potential benefits to wider society, it also raises deep concerns of existential risk, thereby highlighting the need for an ongoing conversation between technology and society. At the core of Curmudgeon concern is the question: What is it to be human in the age of the AI machine? -Editor.

Publisher's Note Springer Nature remains neutral with regard to jurisdictional claims in published maps and institutional affiliations. 